\title{
Bacterial chemotaxis to saccharides is governed by a trade-off between sensing and uptake
}

Noele Norris ${ }^{\text {abc }{ }^{*} \text {, Uria Alcolombri }}{ }^{\mathrm{b}}$, Johannes M. Keegstra ${ }^{\mathrm{b}}$, Yutaka Yawata ${ }^{\mathrm{d}}$, Filippo Menolascina $^{\mathrm{e}}$, Emilio Frazzoli ${ }^{\mathrm{f}}$, Naomi M. Levine ${ }^{\mathrm{c}}$, Vicente I. Fernandez ${ }^{\mathrm{b}}$, and Roman Stocker ${ }^{b^{*}}$

${ }^{a}$ Department of Electrical Engineering and Computer Science, Massachusetts Institute of Technology, Cambridge, MA 02139, USA

${ }^{\mathrm{b}}$ Institute of Environmental Engineering, Department of Civil, Environmental and Geomatic Engineering, ETH Zürich, 8093 Zürich, Switzerland

${ }^{\mathrm{c}}$ Department of Biological Sciences, University of Southern California, Los Angeles, CA 90089, USA

${ }^{\mathrm{d}}$ Faculty of Life and Environmental Sciences, University of Tsukuba, Tsukuba, Japan

e School of Engineering, Institute for Bioengineering, The University of Edinburgh, Edinburgh, EH9 $3 D W, U K$

${ }_{\mathrm{f}}^{\mathrm{f}}$ Department of Mechanical and Process Engineering, Institute for Dynamic Systems and Control, ETH Zürich, Switzerland

${ }^{+}$Current address: Ecology Department, Earth and Environmental Sciences, Lawrence Berkeley National Laboratory, Berkeley, CA, USA

* To whom correspondence may be addressed: noelen@alum.mit.edu, romanstocker@ethz.ch

Keywords: bacterial chemotaxis, $\mathrm{ABC}$ transport, porin-limited transport, molecular-level model, population-level motility assay

This PDF file includes: Main text with Figures 1 to 5. 


\section{Abstract}

40 To swim up gradients of nutrients, E. coli senses nutrient concentrations within its

41 periplasm. For small nutrient molecules, periplasmic concentrations typically match

42 extracellular concentrations. However, this is not necessarily the case for saccharides,

43 such as maltose, which is transported into the periplasm via a specific porin. Previous

44 observations have shown that under various conditions E. coli limits maltoporin

45 abundance so that, for extracellular micromolar concentrations of maltose, there are

46 predicted to be only nanomolar concentrations of free maltose in the periplasm. Thus, in

47 the micromolar regime, the total uptake of maltose from the external environment into the

48 cytoplasm is limited not by the abundance of cytoplasmic transport proteins but by the

49 abundance of maltoporins. Here we present results from experiments and modeling

50 showing that this porin-limited transport enables E. coli to sense micromolar gradients of

51 maltose despite having a high-affinity $\mathrm{ABC}$ transport system that is saturated at these

52 micromolar levels. We used microfluidic assays to study chemotaxis of E. coli in various

53 gradients of maltose and methyl-aspartate and leveraged our experimental observations to

54 develop a mechanistic transport-and-sensing chemotaxis model. Incorporating this model

55 into agent-based simulations, we discover a trade-off between uptake and sensing:

56 although high-affinity transport enables higher uptake rates at low nutrient

57 concentrations, it severely limits dynamic sensing range. We thus propose that E. coli

58 may limit periplasmic uptake to increase its chemotactic sensitivity, enabling it to use

59 maltose as an environmental cue.

60

61 


\section{Statement of Significance}

63 Bacterial chemotaxis is among the best-studied systems in biology and is paradigmatic of

64 the mechanisms used by cells to link sensory inputs with regulated responses, thus

65 providing insight into the ecological basis of cellular physiology. Here we present a

66 mechanistic chemotaxis model that describes how the regulation of the transport of a

67 sugar into and out of the cell's periplasm affects the cell's motile response to that sugar.

68 Based on observations from population-level chemotaxis assays, we uncover an

69 ecologically relevant trade-off between sensing and uptake. The general finding of this

70 work is that, while high-affinity transport allows for higher uptake rates, it can severely

71 limit the cell's dynamic sensing range.

\section{Introduction}

74 Many bacterial species can swim to actively seek environments favorable for growth.

75 These species employ chemotaxis, in which they follow chemical gradients by biasing

76 their swimming direction in response to temporal measurements of their environment (1).

77 Chemotaxis allows cells to find and exploit chemicals in complex landscapes, such as the

78 ocean or the human gut $(2,3)$. This makes them excellent microscale source-seekers $-\mathrm{a}$

79 trait that could allow bacteria to be re-engineered and deployed as "microbots" for a

80 variety of tasks, such as bioremediation (4-6) and targeted medical treatment $(7,8)$. The

81 chemicals that act as attractants for chemotaxis are often metabolic resources for bacteria.

82 However, the precise relationship between chemotaxis and the benefit in confers, either

83 directly through increased uptake of nutrients or indirectly as sensory cues that direct

84 bacteria into more favorable environments, is less clear and has become a focus of recent 
85 chemotaxis research (9-11). Here we demonstrate how the cell's ability to sense a

86 nutrient depends on the expression levels of the proteins involved in the uptake of that

87 nutrient. Therefore, a molecular-level understanding of the interplay between sensing and

88 uptake is needed to predict chemotactic responses.

89 A mechanistic understanding of bacterial chemotaxis has developed over decades

90 of research on model organisms, particularly Escherichia coli. An E. coli cell swims with

91 a "run-and-tumble" pattern, swimming straight before randomly re-orienting by

92 transiently switching the direction of rotation of the flagellar motors (2). The durations of

93 the runs are controlled by a signal-transduction pathway so that attractant binding events

94 at the membrane-bound receptors inhibit motor switches. An additional pathway links

95 rates of methylation and demethylation of the chemoreceptors to the rate of attractant

96 binding events, allowing the cell to store a short-term memory of past measurements and

97 to adapt to background levels of attractant (12-17). The cell thus senses a gradient by

98 measuring the attractant concentration over time and performs chemotaxis by modifying

99 the probability of the next tumbling event in response to the gradient. This behavior has

100 been accounted for in numerous models of chemotaxis. For example, the agent-based

101 Signaling Pathway-based E. coli Chemotaxis Simulator (SPECS) incorporates a

102 molecular-level model of chemotaxis to predict the population-level response of cells in

103 environments with gradients of aspartate (18).

Yet existing models do not capture some fundamental cases of chemotaxis, for

105 example when the cell's uptake of the attractant limits that attractant's periplasmic

106 concentration, as is the case for E. coli's uptake of the sugar maltose. E. coli's

107 chemotactic response to maltose presents a puzzle because, while all other known E. coli 
108 sugar chemoattractants are sensed by the minor receptor $\operatorname{Trg}(19)$, maltose is sensed by

109 the more abundant aspartate receptor, Tar. Maltose and aspartate are sensed

110 independently by Tar because they can bind simultaneously to distinct sites on the

111 receptor (20), so Tar effectively acts as two distinct receptors sharing the same

112 methylation state. Yet, while $E$. coli can respond to concentrations of aspartate over a few

113 orders of magnitude (21), the dynamic range of $E$. coli's response to maltose spans just

114 one order of magnitude $(19,22)$.

Previous work argued that the narrow dynamic range of maltose sensing in E. coli

116 mirrors its narrow dynamic range of sensing of other sugars because the sugars bind

117 indirectly to their cognate receptor (19). While aspartate binds directly to Tar, maltose

118 binds to Tar only when in complex with the maltose binding protein, MalE $(22,23)$.

119 Neumann and coworkers proposed an indirect-binding chemotaxis model to account for

120 the effects of the binding protein (19). However, their model assumes that the

121 concentration of free sugars in the cell periplasm is equal to that in the external

122 environment, which is not the case for maltose chemotaxis (24).

123 The discrepancy between periplasmic and extracellular concentrations of maltose

124 is due to the relatively large size of the maltose molecule. Under approximately steady-

125 state conditions, the periplasmic concentration of a free substrate is equal to its external

126 concentration when the maximal rate at which the substrate can diffuse into the periplasm

127 (that is, the rate of diffusion when no substrate is present in the periplasm) is greater than

128 the rate of uptake of the substrate into the cytoplasm. This is not necessarily the case for

129 saccharides, which diffuse through general porins at rates that are orders of magnitude

130 lower than those of smaller molecules, such as amino acids (25). Because slow rates of 
131 diffusion limit uptake (26), bacteria have evolved specialized porins that facilitate the

132 transport of specific sugars into the periplasm (27). Thus, a cell can regulate the

133 abundance of a particular sugar in its periplasm by regulating the expression of the

134 corresponding porin. This in turn allows the cell to regulate its chemotactic sensitivity to

135 a sugar by altering the amount of that sugar available for a receptor to sense $(28,29)$.

Previous experiments showed that at extracellular concentrations of

137 approximately $1 \mu \mathrm{M}$ of maltose, the total rate of maltose uptake into the cytoplasm

138 decreased proportionally with decreasing abundance of the specific maltose porin, LamB

$139(24,30)$. Thus, in the micromolar regime, transport is porin-limited. In addition, because

140 of very high concentrations of the maltose binding protein MalE, which scavenges for

141 maltose in the periplasm, the great majority of maltose in the periplasm is bound rather

142 than free. Therefore, when maltose is present in micromolar concentrations in the

143 environment, there are estimated to be significantly lower concentrations of free maltose

144 within the periplasm $(24,26,30-34)$. Indeed, Tan and coworkers recently suggested that

145 the periplasmic concentration of free maltose must be lower than the extracellular

146 concentration, based on a discrepancy they found when fitting data of E. coli capillary

147 assays to their population-level chemotaxis model, which accounted for indirect binding

148 (35).

To explore the implications of porin-limited transport on chemotaxis, here we

150 develop a detailed molecular-level chemotaxis model that fully accounts for transport

151 dynamics. The model explicitly accounts for the transport of maltose into the periplasm

152 via the maltoporin $\operatorname{LamB}(28,36)$, and out of the periplasm and into the cytoplasm via the

$153 \mathrm{ABC}$ maltose transporter $\mathrm{MalFGK}_{2}$ (33) (Figure 1). Our transport-and-sensing 
154 chemotaxis model incorporates the impact of variable porin and transporter expression on

155 the chemotactic response. Importantly, due to the limiting concentrations of free maltose

156 in the periplasm, our model removes the common simplifying assumption that the free

157 periplasmic concentration of the sensed substrate is independent of the abundance of

158 chemoreceptors $(19,35,37)$ and instead explicitly considers how the chemotactic signal

159 is a function of chemoreceptor abundance.

160 To benchmark our model, we fit it separately to both previous chemotaxis FRET

161 assays (19) and population-level microfluidic experiments that we conducted to quantify

162 E. coli's behavior in gradients of the sugar maltose, either by itself or in opposing

163 gradients of $\alpha$-methyl-DL-aspartate (MeAsp), a non-metabolizable analog of aspartate.

164 Our model indicates that E. coli's narrow dynamic range of maltose sensing is the result

165 of a trade-off between sensing and uptake. The use of binding proteins allows the cell to

166 achieve high-affinity transport $(34,38)$ but severely limits the concentration of free

167 maltose in the periplasm so that, to sense maltose gradients, the receptor must bind to the

168 maltose-binding protein complex rather than to maltose alone. Hence, the use of binding

169 proteins tightly couples sensing with uptake so that, if transport were not porin-limited,

170 the chemotactic sensing range would be dictated by the high affinity of the $\mathrm{ABC}$ transport

171 system. By instead limiting porin abundance, E. coli makes the chemotactic response less

172 sensitive to variations in binding-protein abundance and decouples the regimes at which

173 sensing and cytoplasmic transport saturate. Therefore, although porin-limited transport

174 decreases the total uptake rate at low maltose concentrations, it prevents high-affinity

175 saturation of the chemotactic signal, enabling the cell to sensitively sense micromolar

176 gradients of maltose. 


\section{$178 \quad$ Results}

179 A transport-and-sensing chemotaxis model. Because previous research demonstrated

180 that maltoporin abundance can limit the periplasmic concentration of free maltose, we

181 developed a transport-and-sensing model of chemotaxis that accounts for the transport

182 kinetics of maltose into and out of the cell's periplasm and for the impact of these

183 kinetics on E. coli's sensing of maltose (Figure 1). We provide an outline of the model

184 here, leaving a detailed derivation for Supplemental Appendices $1 \& 2$.

185 During chemotaxis, the instantaneous probability that a cell tumbles is a function

186 of the receptor activity level. We follow previous models and assume that the receptors

187 within a cluster are either all active or all inactive and that the average activity of the

188 clusters, $\langle a\rangle$, is the probability that a receptor cluster is active (37). This probability is a

189 function of the free-energy difference $f$ between the active and inactive states. Following

190 the Heterogeneous Monod-Wyman-Changeux (HMWC) model, which describes the

191 integration of multiple chemotactic signals that share the same methylation dynamics

192 (39-42), we assume that the free-energy differences of the receptor types are additive so

193 that

$$
\langle a\rangle=\left(1+\mathrm{e}^{\mathrm{f}_{\mathrm{m}}(m)+\sum_{r} n_{r} f_{r}}\right)^{-1}
$$

where $f_{\mathrm{m}}(m)$ is the free-energy difference between an active and inactive receptor cluster

196 in the absence of chemoattractants and depends on the average methylation level of the

197 cluster, $m ; n_{r}$ is the number of type- $r$ receptors in a cluster; and $f_{r}$ is the free-energy

198 difference between an active and inactive bound receptor of type $r$ ( $\mathrm{Tu}, 2013)$.

199 The free-energy difference has the following general form (Tu, 2013): 


$$
f_{r}=\log \frac{1+C_{\mathrm{I}}}{1+C_{\mathrm{A}}}
$$

201 where $C_{I}\left(C_{A}\right)$ is the ratio of the probabilities of an inactive (respectively, active) receptor

202 being bound versus unbound. For the case of indirect binding, these ratios are

$$
\mathrm{C}_{\mathrm{I}, \mathrm{A}}=\frac{[\mathrm{R}: \mathrm{BP}: \mathrm{L}]_{\mathrm{I}, \mathrm{A}}}{[\mathrm{R}]_{\text {total }}-[\mathrm{R}: \mathrm{BP}: \mathrm{L}]_{\mathrm{I}, \mathrm{A}}}
$$

204 where $[R]_{\text {total }}$ is the total effective concentration of the tightly clustered receptors in the

205 periplasm; and $[\mathrm{R}: \mathrm{BP}: \mathrm{L}]_{\mathrm{I}, \mathrm{A}}$ is the total concentration of ligand-binding protein complex

206 bound to an inactive (or active) receptor.

207 The quantity $[\mathrm{R}: \mathrm{BP}: \mathrm{L}]_{\mathrm{I}, \mathrm{A}}$ depends on the concentration of bound maltose-MalE

208 complex available for the receptors to bind, [L: BP]. We assume that this concentration is

209 purely a function of the total concentration of binding proteins in the periplasm, $[\mathrm{BP}]_{\text {total }}$;

210 the periplasmic concentration of maltose, $[\mathrm{L}]_{\mathrm{p}}$; and the dissociation constant of the two

211 compounds, $K_{\mathrm{BP}}$ :

$$
[\mathrm{L}: \mathrm{BP}] \approx \frac{[\mathrm{BP}]_{\mathrm{total}}[\mathrm{L}]_{\mathrm{p}}}{\mathrm{K}_{\mathrm{BP}}+[\mathrm{L}]_{\mathrm{p}}}
$$

213 We solve for $[\mathrm{L}]_{\mathrm{p}}$ as a function of $[\mathrm{L}]_{\text {ext }}$ by assuming a quasi-steady-state equilibrium in

214 which the rate of maltose transport into the periplasm, $v_{\mathrm{p}}$, is equal to the rate of its

215 transport out of the periplasm and into the cytoplasm, $v_{c}$, where

$$
v_{\mathrm{c}}=V_{\mathrm{c}}\left(\frac{[\mathrm{BP}]_{\text {total }}}{K_{\mathrm{c}}+[\mathrm{BP}]_{\text {total }}}\right)\left(\frac{[\mathrm{L}]_{\mathrm{p}}}{\frac{K_{\mathrm{c}} K_{\mathrm{BP}}}{K_{\mathrm{c}}+[\mathrm{BP}]_{\text {total }}}+[\mathrm{L}]_{\mathrm{p}}}\right) \text {; }
$$

$$
v_{\mathrm{p}}=V_{\mathrm{p}} \frac{[\mathrm{L}]_{\mathrm{ext}}-[\mathrm{L}]_{\mathrm{p}}}{K_{\mathrm{p}}+[\mathrm{L}]_{\mathrm{ext}}+[\mathrm{L}]_{\mathrm{p}}}
$$

$218 V_{\mathrm{c}}\left(V_{\mathrm{p}}\right)$ is the maximal cytoplasmic (periplasmic) uptake rate, which is a function of the

219 number of expressed $\mathrm{ABC}$ transporters (porins); $K_{\mathrm{p}}$ is the half-saturation constant of the 
220 porin; and $K_{\mathrm{c}}$ is the dissociation constant between the maltose-MalE complex and the

221 ABC transporter.

222

As a result of our assumption of low periplasmic concentrations of maltose, we

223 cannot make the common simplifying assumption that the free periplasmic

224 chemoattractant concentration is independent of the abundance of chemoreceptors (19,

$22535,37)$. We instead assume that the concentration of bound receptors is

$$
[\mathrm{R}: \mathrm{BP}: \mathrm{L}]_{\mathrm{I}, \mathrm{A}} \approx \frac{\left([\mathrm{R}]_{\text {total }}-[\mathrm{R}: \mathrm{BP}: \mathrm{L}]_{\mathrm{I}, \mathrm{A}}\right)\left([\mathrm{L}: \mathrm{BP}]-[\mathrm{R}: \mathrm{BP}: \mathrm{L}]_{\mathrm{I}, \mathrm{A}}\right)}{K_{\mathrm{I}, \mathrm{A}}}
$$

227 where $K_{\mathrm{I}, \mathrm{A}}$ are the dissociation constants between the inactive (or active) receptor, $\mathrm{R}$, and

228 the maltose-binding protein complex, L: BP. We expand Eq. 7 to the form of a quadratic

229 equation and take its positive root as the solution for [R: BP: $\mathrm{L}]_{\mathrm{I}, \mathrm{A}}$. As we will find below,

230 it is this new, quadratic functional form for the concentration of bound receptors that

231 enables good fits to the data.

232 The transport-and-sensing model solves for the free-energy difference (Eq. 1) in

233 terms of the substrate transport kinetics and abundances of substrate, receptors, and

234 binding proteins (Eqs. 2-7). In comparison with the indirect-binding chemotaxis model

235 (19), the transport-and-sensing model introduces four new parameters, which describe the

236 Michaelis-Menten kinetics of the transport of maltose into $\left(K_{\mathrm{p}}, V_{\mathrm{p}}\right)$ and out of $\left(K_{\mathrm{c}}, V_{\mathrm{c}}\right)$ the

237 periplasm. Based on prior observations, we set $K_{\mathrm{p}}=10 \mathrm{mM}(43), K_{\mathrm{c}}=100 \mu \mathrm{M}(44)$, and

$238 \mathrm{~K}_{\mathrm{BP}}=2 \mu \mathrm{M}(32)$. We take as the free parameters the unknown receptor binding

239 constants, $K_{\mathrm{I}}$ and $K_{\mathrm{A}}$, as well as the parameters that may potentially vary with cellular

240 regulation, $[\mathrm{R}]_{\text {total }},[\mathrm{BP}]_{\text {total }}$, and $V_{\mathrm{c}} / V_{\mathrm{p}}$. To obtain a predictive model of maltose

241 chemotaxis, we fit these five free parameters to experimental data. 
243 E. coli's population-level chemotactic response to maltose. We conducted chemotaxis

244 experiments using a three-channel microfluidic device. The device creates steady,

245 linearly varying concentrations of one or more chemoattractants within a central test

246 channel by flowing two distinct concentrations of the chemoattractants in two source

247 channels located on either side of the test channel and relying on diffusion through the

248 hydrogel barrier in between $(45,46)$ (Figure 2, Methods). To create environments with

249 linear concentration profiles of maltose, we placed a buffer solution with no maltose in

250 the right source channel and a solution containing maltose in the left source channel.

251 To simplify population-level modeling of the experimental observations, we took

252 several precautions with our experiments. We ensured that the cell densities were

253 sufficiently low and media flow rate sufficiently high so that maltose consumption by the

254 cells was negligible (Methods). We also ensured that the maltose binding protein (MalE)

255 concentrations did not vary over the experiments, as the mal regulon is induced by

256 maltose (47). Indeed, a Western blot analysis of MalE showed no difference in the

257 population-averaged MalE expression levels over the range of maltose concentrations

258 tested for the short time durations of our experiments (Figure S1; Methods).

259 The cells showed a measurable chemotactic response within a narrow range of

260 maltose concentrations created from approximately 0.2 to $20 \mu \mathrm{M}$ of maltose in the left

261 source channel. The cells showed a strong peak response at $4 \mu \mathrm{M}$ of maltose (Figure $3 A$;

262 Methods).

263 To help constrain our model fits, we further measured the chemotactic response in

264 gradients of MeAsp and opposing gradients of maltose and MeAsp, by replacing the 
265 buffer solution in the right source channel with a solution containing MeAsp. The

266 response in single gradients of MeAsp match previous assays (Figure 3B) (48). In the

267 opposing gradients, depending on the concentrations of the two chemoattractants in these

268 opposing-gradient environments, the cells either favored one substrate over the other and

269 accumulated on one side of the test channel, or were indifferent to the combination of

270 opposing gradients and had a flat distribution across the test channel (Figures $3 C, D$ ).

271 Under the culture conditions tested, a flat distribution was observed in opposing gradients

272 created by $2 \mu \mathrm{M}$ of maltose and approximately $6-8 \mu \mathrm{M}$ of MeAsp.

273

274 Fitting the model to molecular-level data. We first fit the transport-and-sensing model

275 directly to molecular-level data from previous FRET assays of the E. coli LJ110 strain

276 (19). For this fitting, we used the data from the attractant dose response as well as of the

277 dynamic range in response to three-fold steps of attractant additions (Methods, Figure

278 S10). We found two different parameter fits that can well describe the FRET assays. One

279 fit predicts protein abundances that match estimates obtained from various previous

280 experimental measurements (Figure S10). However, similar to the original indirect-

281 binding model fitted to the FRET data (19), this fit predicts that the dissociation constants

282 of the bound maltose binding protein to active and inactive $\operatorname{Tar}\left(K_{\mathrm{I}(\mathrm{A}), \mathrm{Mal}}\right)$ are in the

283 millimolar regime, whereas direct measurements of the dissociation constants

284 demonstrated that their values are in the micromolar regime (49).

285 The second obtained fit does achieve dissociation constants that more closely

286 match the measured micromolar values (49) but predicts binding protein abundances of

287 approximately $100 \mu \mathrm{M}$, a factor of ten lower than previous estimates $(23,47)$. It is 
288 possible that the maltose binding-protein concentrations were indeed on the order of 100

$289 \mu \mathrm{M}$ for the strain and culture conditions used in the FRET assays, as this hypothesis is

290 supported by additional FRET assays that showed an increase in chemotactic sensitivity

291 with an increase in binding-protein abundance from an inducible plasmid (19). Our

292 model predicts that increasing binding-protein concentration from a baseline value of 100

$293 \mu \mathrm{M}$ does indeed increase chemotactic sensitivity (Figure S11). We therefore conclude

294 that our transport-and-sensing model is consistent with the molecular-level FRET data.

295 However, we were unable to use these molecular-level fits to directly predict the

296 population-level response of our chemotaxis assays because of a crucial discrepancy: the

297 FRET assays show a larger dynamic sensing range than our chemotaxis assays (Figures 3

298 \& S12). We hypothesize that this may be due to differences in experimental conditions or 299 to differences between strain LJ110 used for the FRET assays and strain RP437 used for 300 our chemotaxis assays. Therefore, we fit our transport-and-sensing model directly to the 301 chemotaxis assays.

\section{Predicting population-level response from a molecular-level understanding. We}

304 attempted to fit both the previous indirect-binding model and our transport-and-sensing

305 model directly to the observed population-level responses by incorporating these

306 molecular-level models into a modified version of the agent-based simulator SPECS (18).

307 This modified version accounts for multiple chemoattractant gradients $(40,42)$ and

308 allows the methylation level to saturate to capture imperfect adaptation (19)

309 (Supplemental Appendix 2, Methods). Due to the intractability of running agent-based

310 simulations within an optimization program, we performed series of parameter sweeps to 
311 find good fits (Methods). For the transport-and-sensing model, we constrained the

312 parameter ranges based on estimates from previous literature, whereas for the indirect-

313 binding model we conducted our search over various series of large sweeps. When fitting

314 the indirect-binding model to our single-gradient maltose chemotaxis assays, we found no

315 choice of parameter values that could capture both the narrow range of maltose sensing

316 and the strong peak response at $4 \mu \mathrm{M}$ of maltose (Figure S2; Methods).

317 On the other hand, we were able to find a good fit to our chemotaxis assays using

318 our transport-and-sensing model (Figure 3; Methods). We found that our transport-and-

319 sensing model captures not only the steady-state cell distributions in the maltose single-

320 gradient chemotaxis assays but also the steady-state cell distributions in the MeAsp

321 experiments and in the opposing-gradient experiments, both of which we conducted to

322 help us constrain our maltose parameter fits. This supports the validity of our model's

323 assumption that transport is porin-limited in the chemotactic regime.

324 Because our model is underdetermined, we obtained our fit by constraining the

325 receptor cooperativity to $\mathrm{n}_{\mathrm{Tar}}=4$, matching the finding that $\mathrm{n}_{\mathrm{Tar}}=6$ for $E$. coli strain

326 LJ110 under similar culture conditions and that the Tar to serine receptor ratio is 1.5

327 times higher in strain LJ110 than in the strain we used, RP437 (19). In addition, to make

328 the parameter sweep tractable, we used literature values for $[\mathrm{R}]_{\text {total }}=20 \mu \mathrm{M}(50)$ and

$329[\mathrm{BP}]_{\text {total }}=1 \mathrm{mM}(23)$. With the three parameters thus constrained, our obtained fit is:

$K_{\mathrm{I}, \mathrm{MeAsp}}=26 \mu \mathrm{M}, \mathrm{K}_{\mathrm{A}, \mathrm{MeAsp}}=260 \mu \mathrm{M}, K_{\mathrm{I}, \mathrm{Mal}}=12 \mu \mathrm{M}, \mathrm{K}_{\mathrm{A}, \mathrm{Mal}}=18 \mu \mathrm{M}$, and $\mathrm{V}_{\mathrm{c}} /$

$331 \mathrm{~V}_{\mathrm{p}}=7.5 \times 10^{-4}($ Figure 3$)$. This fit supports our constraint that $\mathrm{n}_{\mathrm{Tar}}=4$, as the

332 dissociation constants of MeAsp to Tar closely match previous estimates of $K_{\mathrm{I}, \mathrm{MeAsp}}=$ 
$33330 \mu \mathrm{M}$ and $\mathrm{K}_{\mathrm{A}, \mathrm{MeAsp}}=500 \mu \mathrm{M}(19)$ as well as our own fit from the FRET data of

$334 K_{\mathrm{I}, \mathrm{MeAsp}}=27.5 \mu \mathrm{M}$ and $\mathrm{K}_{\mathrm{A}, \mathrm{MeAsp}}=365 \mu \mathrm{M}$ (Figure S10). Additionally, our estimates

335 for the receptor binding constants $\left(K_{\mathrm{I}, \mathrm{Mal}}=12 \mu \mathrm{M}\right.$ and $\left.K_{\mathrm{A}, \mathrm{Mal}}=18 \mu \mathrm{M}\right)$ reasonably match

336 observations that these dissociation constants are in the micromolar range (49). Finally,

337 our fit's estimate that $V_{\mathrm{c}} / V_{\mathrm{p}}=7.5 \times 10^{-4}$ is in line with a rough estimate we obtained

338 previously by fitting our maltose transport model to past experiments that $V_{\mathrm{c}} / V_{\mathrm{p}} \approx$

$3391 \times 10^{-4}(34)$. The consistency of all fitted parameter values with previous observations

340 supports the validity of our transport-and-sensing model. For the obtained fit and taking

$341[\mathrm{~L}]_{\mathrm{ext}}=1 \mu \mathrm{M}$, our model predicts that $[\mathrm{L}: \mathrm{BP}]=14.9 \mu \mathrm{M}$ and $[\mathrm{L}]_{\mathrm{p}}=30.1 \mathrm{nM}($ Figures

$3424 A, B)$. This predicted nanomolar concentration of free maltose in the periplasm

343 furthermore supports our understanding that maltose transport into the cell is severely

344 porin-limited in the chemotactic regime.

345 Because the transport-and-sensing model has one more free parameter than the

346 indirect-binding model (five instead of four), it may not be surprising that it attains better

347 fits (Figures $3 \&$ S2). However, we find that a modified version of the transport-and-

348 sensing model with only three fitting parameters also captures most of the observed

349 chemotactic response. Because our model predicts a linear relationship between the

350 extracellular maltose concentration $[\mathrm{L}]_{\mathrm{ext}}$ and the signal [L: BP] for the majority of the

351 maltose sensing range (Figure $4 B$ ), we additionally fit our data assuming [L: BP] =

$352 \alpha[\mathrm{L}]_{\text {ext }}$ so that there are only three free parameters: $K_{\mathrm{I}} / \alpha, K_{\mathrm{A}} / \alpha$, and $[\mathrm{R}]_{\text {total }} / \alpha$

353 (Supplemental Appendix 1). The reduced model captures the observed responses, except 
354 for the saturation of the response at $20 \mu \mathrm{M}$ maltose that is due to the, in fact, sigmoidal

355 relationship between $[\mathrm{L}: \mathrm{BP}]$ and $[\mathrm{L}]_{\text {ext }}$ (Figures $4 \mathrm{~B} \& \mathrm{~S} 3$ ).

356 The ability of our reduced model to capture most of the chemotactic response

357 shows that the improved fit of our full model is not due to increased degrees of freedom.

358 Instead, the predictive power of the transport-and-sensing model is due to the new form

359 of the model, specifically the quadratic form of the equation used to solve for the

360 concentration of bound receptors (Eq. 7). This new form accounts for the dependence of

361 limiting free attractant concentrations on receptor abundance and thereby demonstrates

362 the importance of accounting for the relative rates of periplasmic and cytoplasmic

363 transport to predict the chemotactic response.

A tug-of-war between sensing and uptake explains E. coli's narrow sensing range for

366 maltose. Our fitted maltose transport model (Eqs. 4-6) indicates that maltose uptake

367 becomes severely porin-limited (i.e., $[\mathrm{L}]_{\mathrm{p}} \ll[\mathrm{L}]_{\mathrm{ext}}$ ) for extracellular maltose

368 concentrations $[\mathrm{L}]_{\text {ext }} \lesssim 5 \mu \mathrm{M}$ (Figure $4 A$ ), corroborating previous experimental work (32,

36933 ). If maltose transport was instead never limited by maltoporin abundance (so that

$\left.370[\mathrm{~L}]_{\mathrm{p}}=[\mathrm{L}]_{\mathrm{ext}}\right)$, we predict that, due to the high abundance of binding proteins, the

371 maltose uptake affinity could be approximately one order of magnitude higher (34), thus

372 permitting higher uptake rates at low extracellular maltose concentrations.

373 However, our chemotaxis model indicates that, if the cell were to thus increase

374 porin abundance to increase affinity, it would lose its ability to sense maltose gradients in

375 the micromolar regime. Keeping all else equal but assuming that transport is not porin- 
376 limited (so that $[\mathrm{L}: \mathrm{BP}] \approx[\mathrm{BP}]_{\text {total }}[\mathrm{L}]_{\mathrm{ext}} /\left(K_{\mathrm{BP}}+[\mathrm{L}]_{\mathrm{ext}}\right) ;$ Supplemental Appendix 1$)$, our

377 model indicates that the chemoreceptors would saturate at lower extracellular maltose

378 concentrations so that the dynamic sensing range would shift down and the peak response

379 would occur at $\sim 200 \mathrm{nM}$ of maltose rather than at $\sim 4 \mu \mathrm{M}$ (Figure S4). This occurs

380 because the maltose binding protein MalE is required for both uptake and sensing; thus,

381 the uptake affinity and chemotactic sensitivity are tightly coupled. Therefore, if uptake

382 saturates at lower extracellular concentrations, the chemotactic response saturates at

383 lower concentrations as well.

There is thus a sensing-uptake trade-off. Although higher affinity allows higher uptake rates at low saccharide concentrations, it precludes the ability of bacteria to sense

386 gradients of these nutrients at ecologically relevant micromolar concentrations. This tug-

387 of-war between increasing affinity_by increasing outer-membrane permeability via

388 increased maltoporin expression - and increasing sensing range by decreasing

389 permeability (Figure S5) provides an explanation for E. coli's narrow sensing range for

390 maltose.

391

392

\section{E. coli's chemotactic response is insensitive to variations in binding protein}

393 abundance. To test the ability of our transport-and-sensing model to

394 predict how variable protein expression levels affect the chemotactic response of cells,

395 we performed additional microfluidic experiments to compare the chemotactic response

396 of cells from the original culture conditions - in which cells had no prior exposure to

397 sugars — with the response of cells grown in medium supplemented with $500 \mu \mathrm{M}$ of

398 maltose. We conducted an opposing-gradient chemotaxis assay using concentrations of 
maltose $(2 \mu \mathrm{M})$ and MeAsp $(10 \mu \mathrm{M})$ for which neither chemoattractant response was

400 saturated (Figures $3 A, B$ ). Counterintuitively, cells grown in maltose had a lower relative

401 affinity to maltose than cells grown without maltose (Figure 5A). This was especially

402 surprising because cells grown in maltose had greater maltose-binding protein

403 abundances. As quantified by Western blots, the abundances were nearly double the

404 abundances measured when the cells were grown in the original media without maltose

405 (Figure S1). Interestingly, when we grew cells without maltose but harvested in late

406 exponential phase, we found a very similar decrease in affinity for maltose relative to

407 MeAsp (Figure 5A). At higher optical densities Tar levels are elevated (51, 52), and we

408 also measured a similar increase in maltose binding protein for cells grown on maltose

409 and cells grown without maltose but harvested in stationary-phase (Figure S1).

410 The transport-and-sensing model correctly predicts this surprising change in

411 relative affinity, if we allow the parameter values to account for variation in tar

412 expression. We found that if we only increase the MalE levels in our model, the

413 distribution did not obtain a good fit (Figure 5A). However, when we assume that

414 supplementing the growth medium with maltose, like harvesting at higher optical

415 densities, increases the expression of Tar by a moderate 50\% (51) and also assume that

416 the cell maintains a constant ratio of maximal cytoplasmic and periplasmic uptake rates

$417\left(V_{\mathrm{c}} / V_{\mathrm{p}}\right)$ because malK and $\operatorname{lamB}$ are in the same operon (53), our model provides a good

418 fit of the chemotactic response in opposing gradients (Figure 5A). Thus, although the

419 chemotactic response to MeAsp does not depend on Tar expression levels because the

420 free ligand concentration of MeAsp in the periplasm does not depend on receptor

421 concentration, we found the relative chemotactic affinity to maltose to be highly sensitive 
422 to variations in Tar abundance. Yet it was not sensitive to variations in MalE abundance.

423 In fact, our model indicates that the chemotactic response to maltose is independent of

424 binding protein abundance, given that the binding protein abundance is sufficiently high

425 (Figures 5B\&C, S6\&7).

426 On the other hand, our model predicts that if transport were not porin-limited (so

427 that the periplasmic maltose concentration equals the extracellular concentration), the

428 chemotactic response would be highly sensitive to binding protein abundance (Figures S7

$429 \&$ S8). This stark difference in sensitivity is apparent from the functional forms of the

430 chemotactic signal, [L: BP]. When transport is not porin-limited, [L: BP] is directly

431 proportional to binding protein abundance (Eq. 4; Supplemental Appendix 1). However,

432 in the case of porin limitation (Supplemental Appendix 1, Figure 4B), we find

$$
[\mathrm{L}: \mathrm{BP}] \approx\left(\frac{K_{\mathrm{c}}}{K_{\mathrm{p}}}\right)\left(\frac{V_{\mathrm{p}}}{V_{\mathrm{c}}}\right)[\mathrm{L}]_{\mathrm{ext}}
$$

434 which is independent of binding protein abundance but instead a function of the ratio of

435 abundances of maltoporins, LamB, to maltose $\mathrm{ABC}$ transport units, $\mathrm{MalFGK}_{2}$.

436 Because $\operatorname{lam} B$ and $m a l K$ are adjacent genes in the same operon, we hypothesize

437 that E. coli strain RP437 is "hardwired" to maintain a peak chemotactic sensitivity in the

438 micromolar regime. Although protein abundances may vary greatly due to growth

439 conditions and stochasticity, ratios of abundances of proteins expressed from adjacent

440 genes in the same operon vary much less (54). Therefore, in the porin-limited regime, the

441 maltose chemotactic response is robust to variations in maltose transport protein

442 expression levels and is only sensitive to variations in Tar expression levels. 


\section{Discussion}

445 In this work, we developed a transport-and-sensing chemotaxis model, which, unlike

446 previous molecular-level chemotaxis models, does not assume that the periplasmic

447 concentration of a chemoattractant is equal to its extracellular concentration. Rather, it

448 describes the rates of transport of maltose into and out of the periplasm to determine the

449 concentration of maltose-binding protein complex that can bind to receptors. This

450 predictive, mechanistic model captures how E. coli's expression of maltose transport

451 proteins affects its chemotactic response to maltose.

452 We fit the molecular-level parameters of our model both to previous FRET

453 activity level assays of a mutant E. coli strain and also to our population-level,

454 microfluidic chemotaxis experiments. Whereas both the original indirect-binding model

455 and our transport-and-sensing model could explain the FRET data, we found that the

456 indirect-binding model predicted Tar dissociation constants magnitudes higher than

457 previously measured and that only the transport-and-sensing model could fit the FRET

458 data with parameters consistent with previous literature and, in addition, could fit the

459 microfluidic chemotaxis assays in gradients of maltose. This suggests the importance of

460 considering porin-limited transport kinetics to predict population-level chemotactic

461 response.

462 Previous work argued that, because chemoreception occurs in the periplasm,

463 maltose cytoplasmic transport rates can be drastically reduced without affecting maltose

464 chemotaxis $(22,28)$. Our work argues the opposite - that the kinetics of cytoplasmic

465 relative to periplasmic transport is crucial to the chemotactic response. This novel

466 understanding allows us to reinterpret previous experimental work, which found that $E$. 
467 coli cells with mutations in the $\mathrm{MalFGK}_{2}$ transport proteins demonstrated a peak

468 chemotactic response at lower extracellular concentrations of maltose than wild-type cells

469 (22). We conclude that the observed reduction is a direct consequence of the mutants'

470 reduced cytoplasmic transport rates. The reduced cytoplasmic transport rates increase the

471 concentration of free maltose within the periplasm, causing the binding proteins to

472 saturate at lower extracellular maltose concentrations and thus the chemotactic response

473 to peak at lower maltose concentrations as well.

474 The transport-and-sensing chemotaxis model provides insight into the roles of the

475 outer membrane and high-affinity transport systems in the chemotactic response of gram-

476 negative bacteria to substrates that do not quickly diffuse through general porins. This is

477 the case for a variety of chemotaxis systems, such as the pathogenic enteric bacteria

478 Campylobacter jejuni's chemotaxis to host glycans (55) and the marine bacteria Vibrio's

479 chemotaxis to chitin (56). Our analysis of the model indicates that, while binding proteins

480 enable high-affinity uptake of a nutrient, they constrain the chemotactic response. Under

481 low nutrient conditions when cells rely on binding proteins for effective transport, the

482 binding proteins capture the majority of the nutrient in the periplasm so that the free

483 concentration is too low to be sensed directly. Therefore, the cell instead senses the

484 nutrient-binding protein complex, and, thus, the uptake affinity is tightly coupled to

485 chemotactic affinity, creating a sensing-uptake trade-off, in which higher uptake affinities

486 result in lower chemotactic sensing ranges.

487 However, we surprisingly found that, when transport is porin-limited, the

488 chemotactic response is insensitive to small variations in binding protein abundance.

489 Instead, we find that the chemotactic response is highly sensitive to the ratio of porins to 
490 transport units. Yet, in the case of E. coli's maltose transport system, these two proteins

491 are transcriptionally co-regulated — which is also a common network motif in the E coli

492 chemotaxis pathway (57) — so their ratio is expected to show little variation. This

493 robustness of the chemotactic response to variations in maltose transport protein

494 expression levels suggests that $E$. coli may have evolved to maintain a maltose sensing

495 range that is independent of transport rates. Thus, we hypothesize that E. coli may use

496 maltose not only as a nutrient but also as an environmental cue. It is perhaps for this

497 reason that $E$. coli uses the major receptor Tar rather than the minor receptor Trg to sense

498 maltose separately from all other sugars. However, further work is needed to verify

499 whether E. coli cells do, in fact, maintain an invariant sensing range for maltose over a

500 variety of transport conditions.

501 Our model shows that, while a gram-negative bacterium could use binding protein

502 abundances to tune chemotactic response to growth and environmental conditions if

503 transport were not porin-limited, it can also make chemotactic response independent of

504 transport expression levels by making transport porin-limited. Therefore, although the use

505 of binding proteins limits chemotactic sensitivity and thus creates an uptake-sensing

506 trade-off, it provides a variety of mechanisms for the cell to either independently regulate

507 via protein expression or robustly tune its chemotactic sensing affinity to a particular

508 nutrient based on ecologically relevant conditions.

509

510 Materials and Methods

511 Cell culture. We used E. coli strain RP437, obtained from the laboratory of JS Parkinson.

512 As controls for the Western blot analyses, we also used two strains from the ASKA 
513 library: JW1875-AM (del-tar) and JW3994-AM (del-malE). We grew the cultures

514 overnight in tryptone broth $(10 \mathrm{~g} / \mathrm{L}$ Bacto tryptone, $5 \mathrm{~g} / \mathrm{L} \mathrm{NaCl})$ in a shaking incubator at

$51530{ }^{\circ} \mathrm{C}$ and $300 \mathrm{rpm}$, then diluted 1:100 the following morning into fresh tryptone broth.

516 We harvested the cells, unless otherwise noted, when the culture reached $\mathrm{OD}_{600}=0.47$ in

517 the mid-exponential growth phase. The cells had an exponential growth rate of

518 approximately $0.5 \mathrm{~h}^{-1}$. In the one experiment using tryptone broth supplemented with 500

$519 \mu \mathrm{M}$ of maltose as the growth medium, the cells instead had an exponential growth rate of

520 approximately $0.75 \mathrm{~h}^{-1}$. Before their use in experiments, we washed cells twice by

521 centrifuging at $2000 \times g$ for 5 min and diluted to $\mathrm{OD}_{600}=0.05$ in motility medium ( 10

$522 \mathrm{mM}$ potassium phosphate, $0.1 \mathrm{mM}$ EDTA, $1 \mu \mathrm{M}$ methionine, $10 \mathrm{mM}$ lactic acid, $\mathrm{pH} 7$ )

523 and kept the cells in a $4{ }^{\circ} \mathrm{C}$ refrigerator for $30 \mathrm{~min}$.

525 Experimental setup. We performed the chemotaxis assays using a microfluidic device

526 made by sandwiching an agarose gel layer between a glass microscope slide and a

527 polydimethylsiloxane (PDMS) layer patterned with three parallel channels. We created

528 the channels by molding the PDMS onto a silicon wafer with positive relief features. We

529 fabricated the device with the following specifications (46): the channels were $20 \mathrm{~mm}$

530 long, $100 \mu \mathrm{m}$ deep, and $600 \mu \mathrm{m}$ wide, with $400 \mu \mathrm{m}$ spacing between each channel, and

531 the agarose layer was $0.5 \mathrm{~mm}$ thick and consisted of a $3 \%(\mathrm{w} / \mathrm{v})$ solution of agarose in

532 motility medium.

533 Each of the three channels contained an inlet and outlet port. The outer two

534 channels functioned as feeder channels within which a steady flow of media, at a rate of 
$53510 \mu \mathrm{L}$ per minute, was maintained using a syringe pump (Harvard Apparatus PHD 2000).

536 We set the syringe pump to "refill" mode to create a negative pressure that, along with

537 loosely fitting clips, helped create a seal between the PDMS and agarose. We flowed

538 motility medium with maltose (D-maltose monohydrate; Sigma-Aldrich PHR1497) at

539 concentrations of $0-20 \mu \mathrm{M}$ in the left channel, and motility medium with MeAsp ( $\alpha-$

540 methyl-DL-aspartate; Sigma-Aldrich M6001) at concentrations of 0-460 $\mu \mathrm{M}$ in the right

541 channel. As molecules diffuse freely through agarose, the flow of these solutions in the

542 outer channels created constant gradients within the agarose and hence within the central

543 test channel (45). For example, with $2 \mu \mathrm{M}$ of maltose in the left channel and motility

544 medium in the right channel, the cells in the test channel experienced a linear gradient

545 with a slope of approximately $1.4 \times 10^{-3} \mu \mathrm{M} / \mu \mathrm{m}$ and minimum and maximum

546 concentrations of $0.57 \mu \mathrm{M}$ and $1.43 \mu \mathrm{M}$.

547 Initially, the central channel was empty of liquid, so that, after establishing flow

548 in the outer feeder channels, a steady gradient formed within the lower agarose layer over

549 a timescale of $L^{2} / D$, where $L$ is the distance between the two feeder channels and $D$ is the

550 diffusivity of the molecules through agarose. The agarose gel layer has a diffusivity very

551 similar to water, so that, for small molecules, $D \approx 10^{3} \mu \mathrm{m}^{2} / \mathrm{s}$. Therefore, with a $1,400 \mu \mathrm{m}$

552 spacing between the edges of the two outer channels, gradients formed across the agarose

553 layer in about $30 \mathrm{~min}$.

554 Forty-five minutes after the establishment of flow in the outer channels, we

555 pipetted the refrigerated cells into the test channel and sealed the test channel using glass

556 microscope coverslips. The PDMS and agarose completely blocked advection so that 
557 there was no active flow in the central channel; any flow in the central channel was a

558 result of pressure differences between the two ends of the channel and was negligible

559 compared to the swimming speed of the cells. As the channel is only $100 \mu \mathrm{m}$ deep, the

560 upward diffusion of the chemoattractants from the agarose layer reached a steady state in

561 approximately thirty seconds. Thus, the cells quickly experienced a steady gradient in a

562 no-flow environment. The run-and-tumble chemotaxis of $E$. coli yields an effective

563 diffusivity of $D \approx 300 \mu \mathrm{m}^{2} / \mathrm{s}$, so we began data acquisition twenty minutes after the

564 injection of the cells into the test channel, after the bacterial distribution had reached a

565 steady state.

566 It is important to note that, while MeAsp is non-metabolizable, maltose is

567 metabolizable and is consumed during assays. However, the constant flow of nutrients in

568 the outer channel and the low concentration of cells within the test channel ensured that

569 any changes to maltose concentration within the test channel due to consumption were

570 negligible. Specifically, in the concentration regime of our experiments, E. coli cells have

571 an estimated maltose uptake rate of $500 \mathrm{pmoles} / \mathrm{min} / 10^{9}$ cells (36). There were about $4 \times$

$57210^{7}$ cells $/ \mathrm{mL}$ in the test channel above an agarose layer 5 times thicker than the channel,

573 which acted as a repository of the nutrient. Therefore, without replacement of maltose,

574 the cells only reduced the concentration within the channel by at most $50 \mathrm{nM}$ after 20

575 minutes. However, there was in fact replacement, as the wide agarose layer beyond the

576 test channel acted as a source of maltose that was continuously replenished by the flow

577 maintained by the syringe pump.

578 Under our culture conditions, the cells showed an equal preference for $2 \mu \mathrm{M}$ of

579 maltose and 6-8 $\mu \mathrm{M}$ of MeAsp in the opposing-gradient experiments (Figure 3C,D). For 
580 the MeAsp single-gradient experiments, we found the strongest chemotactic response

581 (that is, the steepest steady-state cell distribution in the test channel) when using a MeAsp

582 concentration in the source channel of $46 \mu \mathrm{M}$ (Figure $3 B$ ). We were unable to use

583 population-level data to determine the concentration at which Tar's sensing of MeAsp

584 saturates because the cells are, in fact, repelled by very high concentrations of MeAsp

585 (Figure S9), likely due to $\mathrm{pH}$ taxis (58). Therefore, we analyzed the response of cells to

586 MeAsp concentrations up to $500 \mu \mathrm{M}$, above which increasing the MeAsp concentration

587 caused a drop in $\mathrm{pH}($ Figure $\mathrm{S} 9 B)$.

Data acquisition and analysis. We acquired images of the chemotaxis assays using a

590 Nikon Eclipse TE2000E inverted microscope fitted with a CCD camera. We imaged the

591 cells using phase contrast with a $20 \times$ objective $($ N.A. $=0.45)$. For each experiment, we

592 focused the objective mid-depth and took 1-min videos (at 10 frames per second) of at

593 least 5 different $1-\mathrm{mm}$ segments across the entire length of the test channel (obtaining at

594 least 5 technical replicates per biological replicate).

595 To determine the positions of the bacteria, we analyzed the videos using in-house

596 MATLAB image analysis code that subtracted any non-motile cells. We determined the

597 positions of the bacteria in all frames and thus obtained bacterial position data for 600

598 frames per segment along the channel. There were about 100 bacteria per frame. We

599 replicated each chemotaxis assay 1-3 times, each time using a new cell culture (obtaining

600 1-3 biological replicates for each experimental condition tested). We combined the

601 bacterial position data from the technical replicates to obtain a single distribution per

602 biological replicate. Finding very good agreement between the resulting distributions 
603

604

605

606

607 expression for the empirical distribution used in our model.

615

617 opposing gradients of maltose and MeAsp. We modified the free-energy difference

618 equations in the original SPECS to incorporate both the HMWC model as well as our

619 transport-and-sensing model. We assumed all additional parameters have the same values

620 as provided in SPECS (18). These parameters include the time discretization, swimming

621 velocity, tumble time, methylation dynamics parameters, Hill coefficient of the motor

622 response, and average directional change due to Brownian rotational diffusion. To

623 describe imperfect adaptation, we modified the methylation dynamics so that the

624 methylation level saturates at a maximum level of 4. In our simulations, when a cell hits

625 the boundary, it modifies its orientation so that it faces away from the boundary with a 
626

random angle from a uniform distribution. We used a time step of $0.1 \mathrm{~s}$. To obtain steady-

627 state distributions, we simulated 1,000 cells for eighty minutes of simulated time $(48,000$

628 iterations) and averaged their locations over the final forty minutes of the simulated time.

629 (See code on Github.)

\section{0}

631

632

633

637 code on Github.)

638

641 parameter sweeps to find good fits for SPECS that used either the original indirect-

642 binding model (19) or our transport-and-sensing model to describe the chemotactic

643 response to maltose.

644 Because we were unable to find a good fit using the indirect-binding model, we

645 used multiple parameter sweeps — over a large range and with finer discretizations - to

646 ensure that we were not missing a better fit. Over these various sweeps, we spanned:

$647 \mathrm{~K}_{\mathrm{BP}}=[0.5: 0.1: 3], \mathrm{p}_{0}=[0: 0.05: 0.5], \mathrm{K}_{\mathrm{I}} /[\mathrm{BP}]=[0.2: 0.1: 12: 2: 5050: 10: 500]$, and

$648 \quad \mathrm{~K}_{\mathrm{A}} / \mathrm{K}_{\mathrm{I}}=[1.2: 0.1: 10]$. 
On the other hand, because of the even larger parameter space for our transport-

650 and-sensing model, our approach was to use previous estimates from the literature to

651 constrain the parameter space as much as possible and then show that, even with these

652 constraints, we could find good fits that captured the response of our chemotaxis assays.

653 We constrained the binding protein abundance to $[\mathrm{BP}]_{\text {total }}=1000 \mu \mathrm{M}(59)$, the receptor

654 abundance to $[\mathrm{R}]_{\text {total }}=20 \mu \mathrm{M}(50)$, and the ratio of the cytoplasmic to periplasmic

655 maximal uptake rates to $V_{\mathrm{c}} / V_{\mathrm{p}} \in\left[10^{-5}, 10^{-3}\right]$ (34). We used estimates that the aspartate

656 to serine receptor ratio (Tar/Tsr) is 1.5 times higher in an LJ110 strain than in an RP437

657 strain (19) to constrain the receptor cooperativity to $\mathrm{n}_{\mathrm{Tar}}=4$.

658 To compare fits over our parameter sweeps, we used the following goodness-of-

659 fit measure:

$$
J=\sum_{k} \sum_{x}\left|p_{k}(x)-f_{k}(x)\right|^{2}
$$

661 where $f_{k}(x)\left(p_{k}(x)\right)$ is the smoothed empirical distribution from experiment $k$

662 (simulation $k$ ) and $x$ are 100 binned positions spanning the $600 \mu \mathrm{m}$ channel. To obtain the

663 fits for SPECS with the transport-and-sensing model, we summed over the following

664 single- and opposing-gradient experiments: five maltose single-gradient experiments $(0.2$,

$6652,4,8$, and $20 \mu \mathrm{M}$ maltose), four MeAsp single-gradient experiments (1.15, 4.6, 46, and

$666460 \mu \mathrm{M}$ MeAsp), and eight maltose and MeAsp opposing-gradient experiments $(2 \mu \mathrm{M}$

667 maltose and $0.46,2,4,6,8,10,46$, and $460 \mu \mathrm{M}$ MeAsp). In out attempt to fit SPECS

668 with the indirect-binding model, we summed only over the five maltose single-gradient

669 experiments.

670 
671 Western blot assay of MalE expression. To confirm that there was no change in MalE

672 expression levels over the maltose concentrations and time durations of our experiments,

673 we performed a Western blot analysis of MalE (Figure S1). We cultured, washed, and

674 harvested the cells according to the protocol described above and then placed the cells in

$6753 \mathrm{~mL}$ of motility medium with various concentrations of maltose. Because the cells

676 experienced the maltose gradients for at most 30 minutes in our chemotaxis assays, after

67730 minutes, we froze the samples at $-80{ }^{\circ} \mathrm{C}$ until we performed immunoblotting. To lyse

678 the cells, we added $200 \mu \mathrm{L}$ lysis buffer (50 mM Tris, $100 \mathrm{mM} \mathrm{NaCL,} \mathrm{0.1 \%} \mathrm{Triton} \mathrm{X-100,}$

$679250 \mathrm{U} / \mathrm{mL}$ benzonase nuclease, and $0.4 \mathrm{mg} / \mathrm{mL}$ lyzosyme) into each $3 \mathrm{~mL}$ frozen sample,

680 vortexed, and shook tubes for $30 \mathrm{~min}$ at $37^{\circ} \mathrm{C}$. We then added loading Laemmli buffer

681 (1:4) and incubated at $95^{\circ} \mathrm{C}$ for $5 \mathrm{~min}$. We loaded $10 \mu \mathrm{L}$ of each sample into a pre-

prepared $12 \%$ sodium dodecyl sulfate (SDS) gel (Bio-Rad) and separated the protein by

683 electrophoresis at $100 \mathrm{~V}$ for $1 \mathrm{~h}$ in a Bio-Rad Tetra cell apparatus. We blotted the gel

684 against a polyvinylidene difluoride (PVDF) membrane using transfer buffer (25 mM Tris,

$685190 \mathrm{mM}$ glycine, $20 \%$ methanol) at $100 \mathrm{~V}$ for $1 \mathrm{~h}$. We then blocked the blot using

686 blocking buffer (3\% bovine serum albumin in phosphate buffered saline with tween 20

687 (PBST)) for $1 \mathrm{~h}$ at room temperature. For the primary antibody, we used $1 \mu \mathrm{g} / \mathrm{mL}$ anti-

688 MalE (unconjugated rabbit polyclonal antibody; LS Bio LS-C355688) in blocking buffer

689 for $1 \mathrm{~h}$ at room temperature, and then placed it in a $4^{\circ} \mathrm{C}$ refrigerator overnight. The

690 following morning, we washed the blot three times in PBST. For the secondary antibody,

691 we used 1:5000 goat anti-rabbit IgG secondary antibody (Thermo Fisher 65-6120) in

692 blocking buffer, maintained for $2 \mathrm{~h}$ at room temperature and then washed three times in 
694 covered at room temperature. We acquired images after 10, 30, and 90 minutes exposure.

695 We quantified the bands of the resulting blot using ImageJ software (imagej.nih.gov/ij/)

696 and normalized the intensity of each band by their respective total protein concentrations,

697 obtained by absorbance measurements at $280 \mathrm{~nm}$ (A280) from Thermo-Scientific

698 NanoDrop UV-Vis spectrophotometry.

699

700

Author Contributions: NN, EF, and RS conceived the idea; NN and FM designed the

701 assay experiments; NN and NL developed the model; YY developed the microfluidic

702 device used for the assays; NN performed the chemotaxis experiments, analyzed the

703 results, and fitted the model to the chemotaxis assays and previous FRET reporter assays;

704 FM, JK, and VF contributed to data analysis; UA designed and performed the Western

705 blot experiments; NN, UA, JK, FM, NL, VF, and RS interpreted the results; and NN, JK,

$706 \mathrm{VF}, \mathrm{RS}$, and NL wrote the paper.

707

708 Acknowledgments

709 The authors acknowledge the support of a Gordon and Betty Moore Foundation Marine

710 Microbiology Initiative Investigator Award (grant 3783 to R.S.) and a grant from the

711 Simons Foundation through the Principles of Microbial Ecosystems (PriME)

712 collaboration (to R.S.). Contributions to the editing of this paper by Dr. Russell Naisbit

713 are gratefully acknowledged. N.N. would also like to thank Professor Ned Wingreen for

714 his invaluable feedback. 
717 Code availability: The code used for the agent-based simulations and data fitting is

718 available at: https://github.com/noelenorris/maltose_chemotaxis.git

\section{References}

1. Wadhwa, N., and H.C. Berg. 2021. Bacterial motility: machinery and mechanisms. Nat Rev Microbiol. 1-13.

2. Berg, H.C. 2004. E. coli in Motion. New York: Springer-Verlag.

3. Stocker, R., and J.R. Seymour. 2012. Ecology and Physics of Bacterial Chemotaxis in

4. Lovley, D.R. 2003. Cleaning up with genomics: applying molecular biology to

5. Pandey, G., and R.K. Jain. 2002. Bacterial Chemotaxis toward Environmental Pollutants: Role in Bioremediation. Applied and Environmental Microbiology. 68:5789-5795.

6. Pieper, D.H., and W. Reineke. 2000. Engineering bacteria for bioremediation. Current Opinion in Biotechnology. 11:262-270.

7. Anderson, J.C., E.J. Clarke, A.P. Arkin, and C.A. Voigt. 2006. Environmentally Controlled Invasion of Cancer Cells by Engineered Bacteria. Journal of Molecular Biology. 355:619-627.

8. Forbes, N.S. 2010. Engineering the perfect (bacterial) cancer therapy. Nature Reviews Cancer. 10:785-794.

\section{Yang, Y., A. M. Pollard, C. Höfler, G. Poschet, M. Wirtz, R. Hell, and V. Sourjik.} 2015. Relation between chemotaxis and consumption of amino acids in bacteria. Molecular Microbiology. 96:1272-1282.

10. Wong-Ng, J., A. Celani, and M. Vergassola. 2018. Exploring the function of bacterial chemotaxis. Current Opinion in Microbiology. 45:16-21.

11. Cremer, J., T. Honda, Y. Tang, J. Wong-Ng, M. Vergassola, and T. Hwa. 2019. Chemotaxis as a navigation strategy to boost range expansion. Nature.

12. Alon, U. 2006. An Introduction to Systems Biology: Design Principles of Biological Circuits. CRC Press.

747 13. Barkai, N., and S. Leibler. 1997. Robustness in simple biochemical networks.

$748 \quad$ Nature. 387:913-917. 
749

750

751

752

753

754

755

756

14. Bi, S., and V. Sourjik. 2018. Stimulus sensing and signal processing in bacterial chemotaxis. Current Opinion in Microbiology. 45:22-29.

15. Bray, D., M.D. Levin, and C.J. Morton-Firth. 1998. Receptor clustering as a cellular mechanism to control sensitivity. Nature. 393:85-88.

16. Falke, J.J., R.B. Bass, S.L. Butler, S.A. Chervitz, and M.A. Danielson. 1997. The Two-Component Signaling Pathway of Bacterial Chemotaxis: A Molecular View of Signal Transduction by Receptors, Kinases, and Adaptation Enzymes. Annual Review of Cell and Developmental Biology. 13:457-512.

17. Parkinson, J.S., G.L. Hazelbauer, and J.J. Falke. 2015. Signaling and sensory adaptation in Escherichia coli chemoreceptors: 2015 update. Trends in Microbiology. 23:257-266.

18. Jiang, L., Q. Ouyang, and Y. Tu. 2010. Quantitative Modeling of Escherichia coli Chemotactic Motion in Environments Varying in Space and Time. PLoS Computational Biology. 6:e1000735.

19. Neumann, S., C.H. Hansen, N.S. Wingreen, and V. Sourjik. 2010. Differences in signalling by directly and indirectly binding ligands in bacterial chemotaxis. The EMBO Journal. 29:3484-3495.

20. Mowbray, S.L., and D.E. Koshland. 1987. Additive and independent responses in a single receptor: Aspartate and maltose stimuli on the tar protein. Cell. 50:171-180.

21. Lazova, M.D., T. Ahmed, D. Bellomo, R. Stocker, and T.S. Shimizu. 2011. Response rescaling in bacterial chemotaxis. Proceedings of the National Academy of Sciences. 108:13870-13875.

22. Hazelbauer, G.L. 1975. Maltose chemoreceptor of Escherichia coli. Journal of bacteriology. 122:206-214.

23. Manson, M.D., W. Boos, P.J. Bassford, and B.A. Rasmussen. 1985. Dependence of maltose transport and chemotaxis on the amount of maltose-binding protein. J. Biol. Chem. 260:9727-9733.

24. Brass, J.M., M.D. Manson, and T.J. LARSONt. 1984. Transposon TnlO-Dependent Expression of the lamB Gene in Escherichia coli. J. BACTERIOL. 159:7.

25. Nikaido, H. 2003. Molecular Basis of Bacterial Outer Membrane Permeability Revisited. Microbiol. Mol. Biol. Rev. 67:593-656.

26. Koch, A.L. 1997. Microbial physiology and ecology of slow growth. Microbiol. Mol. Biol. Rev. 61:305-318. 
27. Saier, M.H. 2000. Families of transmembrane sugar transport proteins. Molecular Microbiology. 35:699-710.

28. Hazelbauer, G.L. 1975. Role of the receptor for bacteriophage lambda in the functioning of the maltose chemoreceptor of Escherichia coli. Journal of Bacteriology. 124:119-126.

29. Ingham, C., M. Buechner, and J. Adler. 1990. Effect of outer membrane permeability on chemotaxis in Escherichia coli. Journal of Bacteriology. 172:35773583.

30. Wandersman, C., and M. Schwartz. 1982. Mutations that alter the transport function of the LamB protein in Escherichia coli. Journal of Bacteriology. 151:15-21.

31. Freundlieb, S., U. Ehmann, and W. Boos. 1988. Facilitated diffusion of pnitrophenyl-alpha-D-maltohexaoside through the outer membrane of Escherichia coli. Characterization of LamB as a specific and saturable channel for maltooligosaccharides. J. Biol. Chem. 263:314-320.

32. Hengge, R., and W. Boos. 1983. Maltose and lactose transport in Escherichia coli: Examples of two different types of concentrative transport systems. Biochimica et Biophysica Acta (BBA) - Reviews on Biomembranes. 737:443-478.

33. Nikaido, H. 1994. Maltose transport system of Escherichia coli: An ABC-type transporter. FEBS letters. 346:55-58.

34. Norris, N., N.M. Levine, V.I. Fernandez, and R. Stocker. 2021. Mechanistic model of nutrient uptake explains dichotomy between marine oligotrophic and copiotrophic bacteria. PLOS Computational Biology. 17:e1009023.

35. Tan, P.Y., Marcos, and Y. Liu. 2020. Modelling bacterial chemotaxis for indirectly binding attractants. Journal of Theoretical Biology. 487:110120.

36. Klebba, P.E. 2002. Mechanism of maltodextrin transport through LamB. Research in Microbiology. 153:417-424.

37. Tu, Y. 2013. Quantitative Modeling of Bacterial Chemotaxis: Signal Amplification and Accurate Adaptation. Annual Review of Biophysics. 42:337-359.

38. Bosdriesz, E., S. Magnúsdóttir, F.J. Bruggeman, B. Teusink, and D. Molenaar. 2015. Binding proteins enhance specific uptake rate by increasing the substratetransporter encounter rate. FEBS J. 282:2394-2407.

39. Hart, Y., A.E. Mayo, O. Shoval, and U. Alon. 2013. Comparing Apples and Oranges: Fold-Change Detection of Multiple Simultaneous Inputs. PLoS ONE. $8: \mathrm{e} 57455$. 
40. Keymer, J.E., R.G. Endres, M. Skoge, Y. Meir, and N.S. Wingreen. 2006. Chemosensing in Escherichia coli: two regimes of two-state receptors. Proceedings of the National Academy of Sciences of the United States of America. 103:17861791.

41. Lan, G., S. Schulmeister, V. Sourjik, and Y. Tu. 2014. Adapt locally and act globally: strategy to maintain high chemoreceptor sensitivity in complex environments. Molecular Systems Biology. 7:475-475.

42. Mello, B.A., and Y. Tu. 2005. An allosteric model for heterogeneous receptor complexes: understanding bacterial chemotaxis responses to multiple stimuli. Proceedings of the National Academy of Sciences of the United States of America. 102:17354-17359.

43. Andersen, C. 1995. Evaluation of the rate constants of sugar transport through maltoporin (LamB) of Escherichia coli from the sugar-induced current noise. The Journal of General Physiology. 105:385-401.

44. Austermuhle, M.I., J.A. Hall, C.S. Klug, and A.L. Davidson. 2004. Maltose-binding Protein Is Open in the Catalytic Transition State for ATP Hydrolysis during Maltose Transport. J. Biol. Chem. 279:28243-28250.

45. Ahmed, T., T.S. Shimizu, and R. Stocker. 2010. Bacterial Chemotaxis in Linear and Nonlinear Steady Microfluidic Gradients. Nano Letters. 10:3379-3385.

46. Yawata, Y., O.X. Cordero, F. Menolascina, J.-H. Hehemann, M.F. Polz, and R. Stocker. 2014. Competition-dispersal tradeoff ecologically differentiates recently speciated marine bacterioplankton populations. Proceedings of the National Academy of Sciences. 111:5622-5627.

47. Schlegel, A., A. Bohm, S.-J. Lee, R. Peist, K. Decker, and W. Boos. 2002. Network regulation of the Escherichia coli maltose system. Journal of molecular microbiology and biotechnology. 4:301-307.

48. Kalinin, Y.V., L. Jiang, Y. Tu, and M. Wu. 2009. Logarithmic Sensing in Escherichia coli Bacterial Chemotaxis. Biophysical Journal. 96:2439-2448.

49. Richarme, G. 1982. Interaction of the maltose-binding protein with membrane vesicles of Escherichia coli. J. Bacteriol. 149:662-667.

50. Stock, J.B. 1994. Adaptive responses in bacterial chemotaxis. In: Sibley DR, MD Houslay, editors. Regulation of Cellular Signal Transduction Pathways by Desensitization and Amplification. New York: Wiley. pp. 3-24. 
849

850
51. Kalinin, Y., S. Neumann, V. Sourjik, and M. Wu. 2010. Responses of Escherichia coli Bacteria to Two Opposing Chemoattractant Gradients Depend on the Chemoreceptor Ratio. Journal of Bacteriology. 192:1796-1800.

52. Yoney, A., and H. Salman. 2015. Precision and Variability in Bacterial Temperature Sensing. Biophysical Journal. 108:2427-2436.

53. Boos, W., and A. Böhm. 2000. Learning new tricks from an old dog: MalT of the Escherichia coli maltose system is part of a complex regulatory network. Trends in Genetics. 16:404-409.

54. Zhao, J., H. Zhang, B. Qin, R. Nikolay, Q.-Y. He, C.M.T. Spahn, and G. Zhang. 2019. Multifaceted Stoichiometry Control of Bacterial Operons Revealed by Deep Proteome Quantification. Frontiers in Genetics. 10.

55. Day, C.J., R.M. King, L.K. Shewell, G. Tram, T. Najnin, L.E. Hartley-Tassell, J.C. Wilson, A.D. Fleetwood, I.B. Zhulin, and V. Korolik. 2016. A direct-sensing galactose chemoreceptor recently evolved in invasive strains of Campylobacter jejuni. Nature Communications. 7.

56. Li, X., and S. Roseman. 2004. The chitinolytic cascade in Vibrios is regulated by chitin oligosaccharides and a two-component chitin catabolic sensor/kinase. PNAS. 101:627-631.

57. Kollmann, M., L. Løvdok, K. Bartholomé, J. Timmer, and V. Sourjik. 2005. Design principles of a bacterial signalling network. Nature. 438:504-507.

58. Yang, Y., and V. Sourjik. 2012. Opposite responses by different chemoreceptors set a tunable preference point in Escherichia coli pH taxis. Molecular Microbiology. 86:1482-1489.

59. Boos, W., and H. Shuman. 1998. Maltose/maltodextrin system of Escherichia coli: transport, metabolism, and regulation. Microbiology and Molecular Biology Reviews. 62:204-229. 


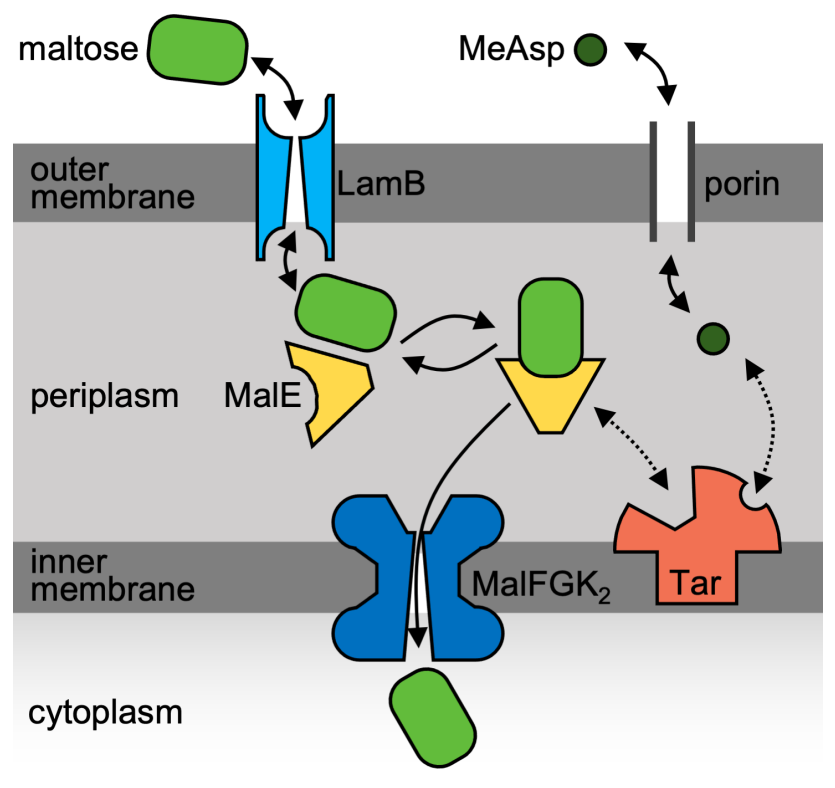

879 Figure 1: Schematic of the transport and sensing of maltose and MeAsp. MeAsp $(\alpha-$ methyl-DL-aspartate, an analog of the amino acid aspartate) enters and exits the periplasm via general diffusive porins, binds directly to the aspartate receptor, Tar, and is not transported into the cytoplasm. Maltose, in contrast, is larger and enters the periplasm

883 via facilitated diffusion by the maltoporin, LamB. The maltose-binding protein (MalE)

884 both $(i)$ binds to the maltose $\mathrm{ABC}$ transporter, $\mathrm{MalFGK}_{2}$, to allow maltose to be

885 transported into the cytoplasm and (ii) allows Tar to sense maltose via a binding site 886 independent of that for MeAsp. 


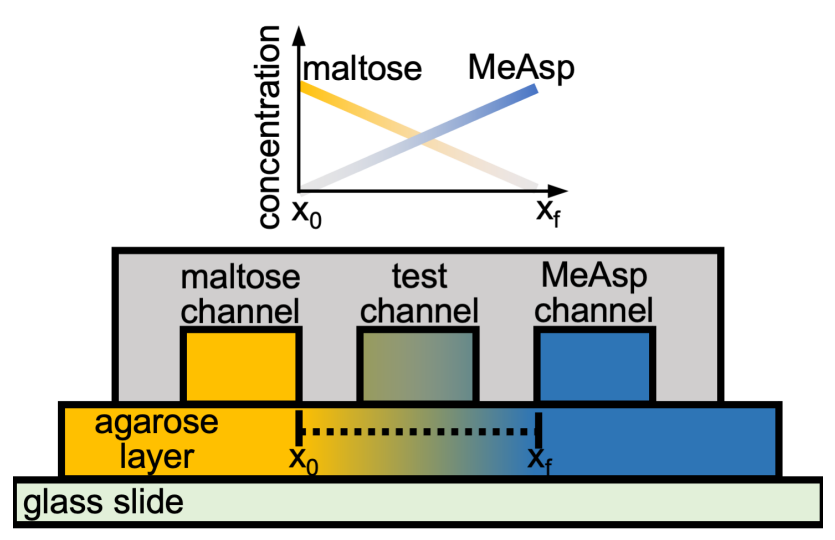

890

891 Figure 2: Side view of the three-channel microfluidic device used to expose cells to

892 constant chemoattractant gradients. The channels, fabricated in solute-impermeable

893 polydimethylsiloxane (PDMS), were $20 \mathrm{~mm}$ long, $100 \mu \mathrm{m}$ deep, $600 \mu \mathrm{m}$ wide, and with

$894400 \mu \mathrm{m}$ spacing between each channel. The agarose layer was $0.5 \mathrm{~mm}$ thick. Motility

895 medium with a constant maltose concentration was flowed through the left outer channel,

896 and motility medium with a constant MeAsp concentration was flowed through the right

897 outer channel. For the opposing-gradient experiments, both the maltose and MeAsp

898 concentrations were nonzero; for the single-gradient experiments, one of the two outer

899 channels contained only motility medium. The chemoattractants diffused through the

900 agarose layer and up into the test channel, creating two steady linear concentration

901 profiles in opposite directions. Figure adapted from Yawata et al., 2014. 
A

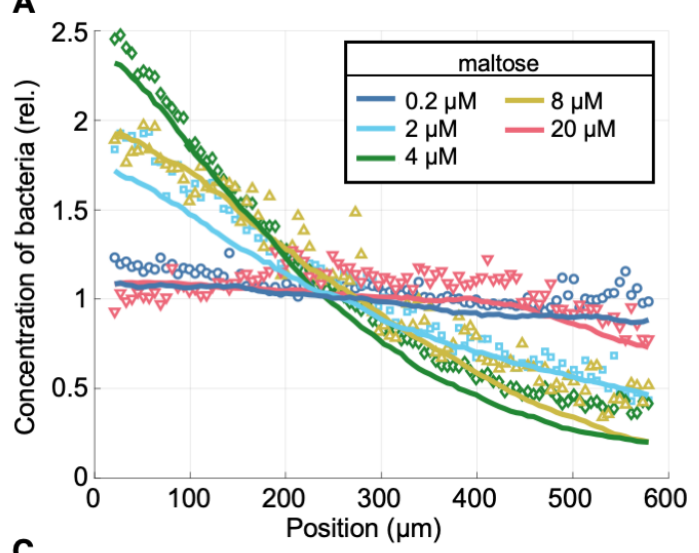

C

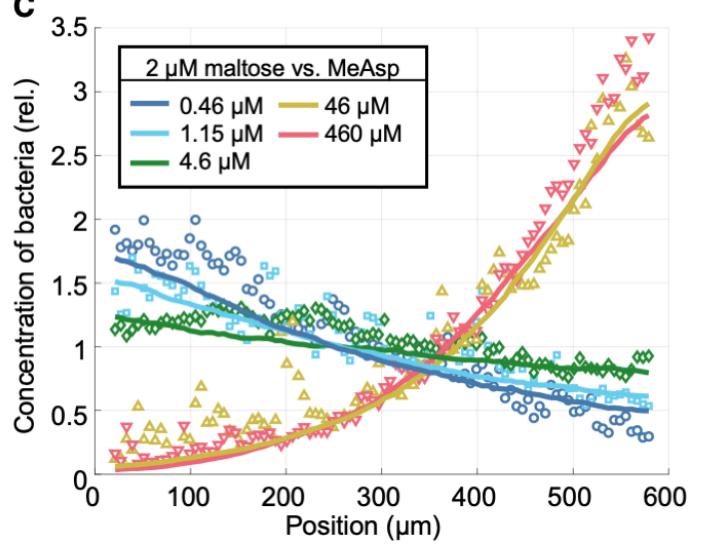

B
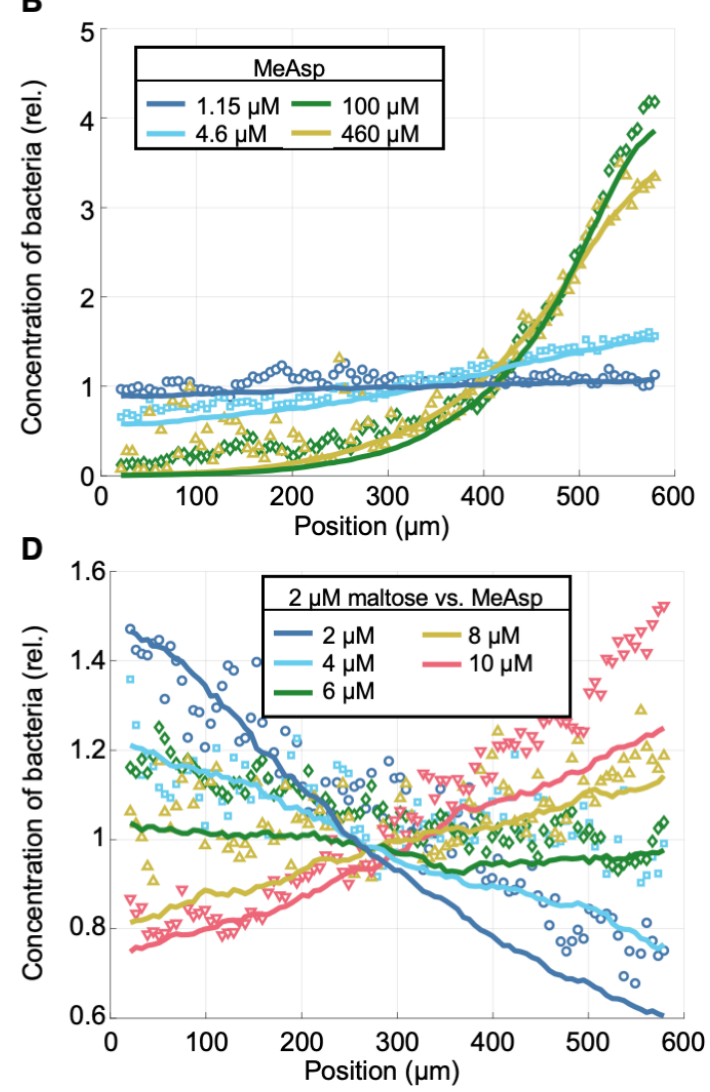

Figure 3: Steady-state distributions from experimental chemotaxis assays in single

904

905

906

\section{and opposing gradients of MeAsp and maltose along with the best fits obtained from}

\section{parameter sweeps of SPECS with the transport-and-sensing model. Each}

experimental distribution of the relative concentration of bacteria was obtained using the bacterial positions measured over all channel locations and biological replicates

(Methods). In each plot, the maximal maltose concentration is at position $\mathrm{x}=0 \mu \mathrm{m}$ and

the maximal MeAsp concentration is at position $\mathrm{x}=600 \mu \mathrm{m}$. Legends give the

chemoattractant concentrations in the outer channels. (A) Single-gradient maltose

experiments. (B) Single-gradient MeAsp experiments. (C) Opposing-gradient

experiments with $2 \mu \mathrm{M}$ of maltose in the left outer channel and various MeAsp

concentrations in the right outer channel. (D) Additional opposing-gradient experiments 
bioRxiv preprint doi: https://doi.org/10.1101/2021.11.05.467490; this version posted November 6, 2021. The copyright holder for this preprint (which was not certified by peer review) is the author/funder, who has granted bioRxiv a license to display the preprint in perpetuity. It is made available under aCC-BY-NC-ND 4.0 International license.

914 with $2 \mu \mathrm{M}$ of maltose in the left outer channel and further intermediate MeAsp

915 concentrations in the right outer channel. 

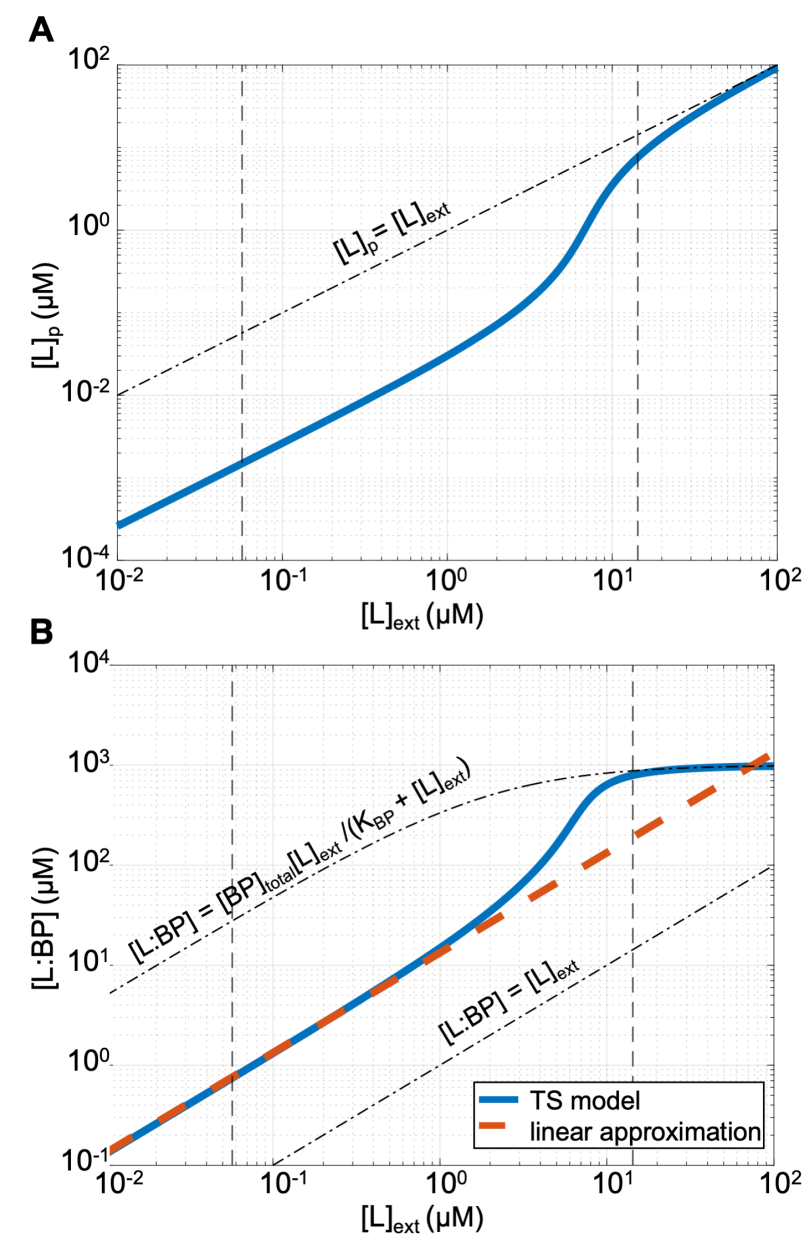

917 Figure 4: Maltose transport. The transport-and-sensing (TS) model's predictions of (A)

918 periplasmic free maltose concentration, $[\mathrm{L}]_{\mathrm{p}}$, and (B) maltose-binding protein complex

919 concentration, [L:BP], as a function of extracellular maltose concentration using best fit

920 of chemotaxis assays from parameter sweep. Vertical dashed lines show the minimum

921 and maximum maltose concentrations experienced by cells in our experiments. Although

922 the chemotactic signal [L:BP] has a sigmoidal form, it is linear for the majority of the

923 chemotactic sensing range. Thus, we obtain good fits for the observed chemotactic

924 response using the linear approximation (red dashed line) $[\mathrm{L}: \mathrm{BP}] \approx \alpha[\mathrm{L}]_{\mathrm{ext}}$ with $\alpha=$

$925:\left(K_{\mathrm{c}} / K_{\mathrm{p}}\right)\left(V_{\mathrm{p}} / V_{\mathrm{c}}\right)=13.3$. Note that $[\mathrm{L}: \mathrm{BP}]$ is about an order of magnitude higher than 
bioRxiv preprint doi: https://doi.org/10.1101/2021.11.05.467490. this version posted November 6, 2021. The copyright holder for this preprint (which was not certified by peer review) is the author/funder, who has granted bioRxiv a license to display the preprint in perpetuity. It is made available under aCC-BY-NC-ND 4.0 International license.

926 the external maltose concentration $[\mathrm{L}]_{\mathrm{ext}}$ in the chemotactic regime and approaches

$927[\mathrm{~L}: \mathrm{BP}] \approx[\mathrm{BP}]_{\text {total }}[\mathrm{L}]_{\mathrm{ext}} /\left(K_{\mathrm{BP}}+[\mathrm{L}]_{\mathrm{ext}}\right)$ at high external concentrations, where transport

928 is no longer porin-limited so $[\mathrm{L}]_{\mathrm{p}}=[\mathrm{L}]_{\text {ext }}$. 

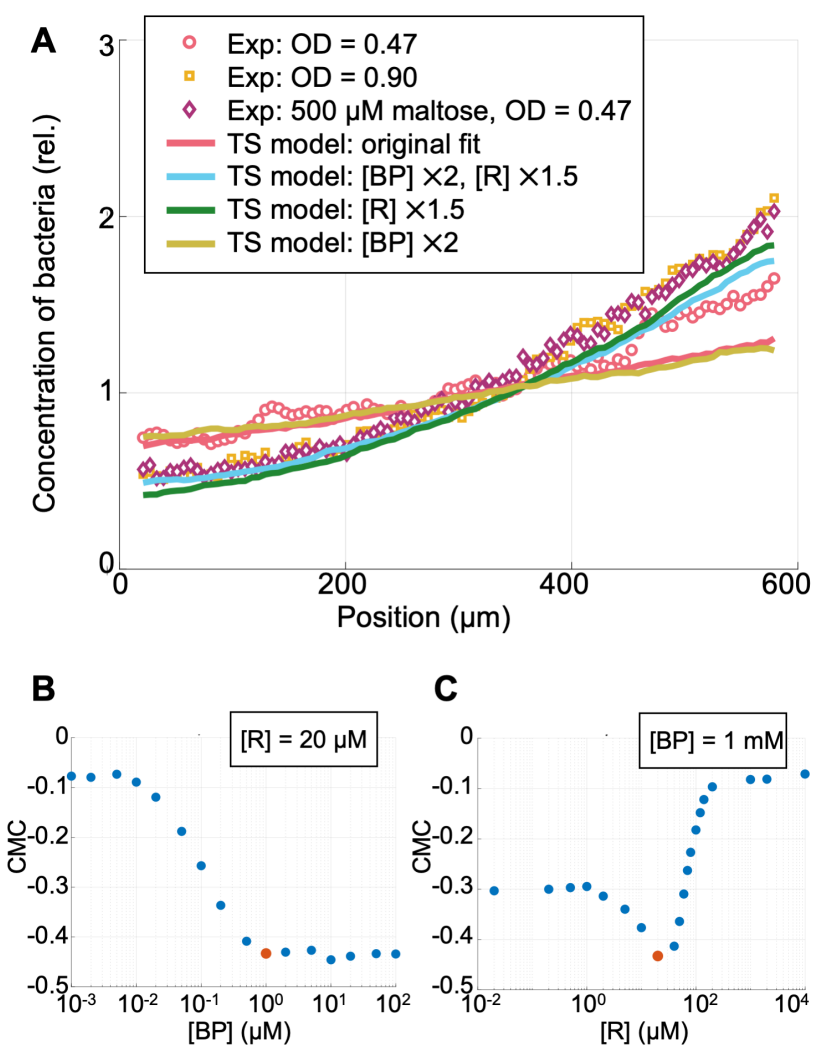

930 Figure 5: Sensitivity of chemotactic response to variations in binding protein and

931 receptor abundances. (A) Steady-state distributions from experimental chemotaxis

932 assays in opposing gradients created using $2 \mu \mathrm{M}$ maltose and $10 \mu \mathrm{M}$ MeAsp for cells

933 obtained from different culture conditions. Cells were cultured in tryptone broth and

934 harvested as in other experiments at mid-exponential phase $(\mathrm{OD}=0.47)$, harvested at

935 late-exponential phase $(\mathrm{OD}=0.90)$ when the abundance of Tar is known to be higher, or

936 cultured in tryptone broth supplemented with $500 \mu \mathrm{M}$ maltose and harvested at OD =

9370.47 , and then placed in the microfluidic chamber with $2 \mu \mathrm{M}$ maltose in the left channel

938 and $10 \mu \mathrm{M}$ MeAsp in the right channel. Curves show fits obtained using an analytical

939 approximation of the transport-and-sensing (TS) model, with variants modifying, by the

940 specified factor, the concentration of MalE, [BP], and the concentration of Tar, [R]. Note 
941 that, for increases in [R] by $50 \%$, we also increased $\mathrm{n}_{\text {Tar }}$ by $50 \%$ to a value of $\mathrm{n}_{\text {Tar }}=6$.

942 These results demonstrate that the relative chemotactic abundance is sensitive to Tar

943 abundance but not to binding protein abundance. (B\&C) We use our fitted SPECS model

944 to predict the peak chemotactic response, at $4 \mu \mathrm{M}$ of maltose, as a function of both

945 binding protein abundance (with receptor abundance held constant at $20 \mu \mathrm{M}, \mathrm{B}$ ) and

946 effective chemoreceptor abundance (with binding protein abundance held constant at 1

$947 \mathrm{mM}, \mathrm{C})$. To quantify the response, we use the chemotaxis migration coefficient (CMC),

948 which is defined as CMC $=\frac{\langle\mathrm{x}\rangle-300}{300}$, where $\langle\mathrm{x}\rangle$ is the average position in microns of the

949 cells across the $600 \mu \mathrm{m}$ channel. Our model suggests that the chemotactic response does

950 not vary for sufficiently high binding protein abundances but is very sensitive to

951 variations in receptor abundance. The red dots indicate the responses at $4 \mu \mathrm{M}$ maltose

952 using our original estimate of the cells' average binding protein abundance and receptor

953 abundance when grown in tryptone and harvested at $\mathrm{OD}=0.47$. 